\title{
CRITÉRIOS PARA ESCOLHA DO ACOMPANHANTE DURANTE O TRABALHO DE PARTO
}

\author{
CRITERIA FOR CHOOSING THE \\ COMPANION DURING LABOR
}

\section{CRITERIOS PARA ELEGIR EL ACOMPAÑANTE DURANTE EL TRABAJO DE PARTO}

\author{
Torcata Amorim ${ }^{1}$ \\ Larissa Aarestrup de Aquino Aguiar ${ }^{2}$ \\ Mariana de Assis Cabral Pereira ${ }^{3}$ \\ Juliana de Oliveira Marcatto ${ }^{4}$ \\ Kelly Cristina Almeida Borgonove 5
}

Como citar esse artigo: Amorim T, Aguiar LAA, Pereira MAC, Marcatto JO, Borgonove KCA. Critérios para escolha do acompanhante durante o trabalho de parto. Rev baiana enferm. 2020;34:e36833.

Objetivo: descrever os critérios que levam a parturiente a escolher o seu acompanhante durante o trabalho de parto. Método: estudo descritivo de abordagem qualitativa, desenvolvido na maternidade de um hospital público de ensino de Belo Horizonte, Minas Gerais, Brasil. Participaram 17 puérperas maiores de 18 anos. Para a coleta de dados foi utilizada a entrevista semiestruturada. Utilizou-se a análise de conteúdo para explorar as falas. Resultados: o critério de escolha foi o vínculo do acompanhante com a puérpera ou a disponibilidade no momento. A maioria era o próprio companheiro e pai do recém-nascido. Na análise, as falas foram organizadas em uma categoria - Critérios de escolha do acompanhante - e quatro subcategorias: Como as participantes informaram-se sobre o direito de ter um acompanhante; Reações geradas pela presença do acompanhante; Atitudes do acompanhante que causaram incômodo; Desejo de ter outro acompanhante. Conclusão: a participação paterna mostrou-se um critério relevante para as parturientes.

Descritores: Acompanhantes de Pacientes. Trabalho de Parto. Cuidados de Enfermagem. Parto Humanizado.

Objective: to describe the criteria that lead the parturient to choose her companion during labor. Method: descriptive study with a qualitative approach, developed in the maternity of a public teaching hospital in Belo Horizonte, Minas Gerais, Brazil. The participants 17 puerperas aged over 18 years. For data collection, the semi-structured interview was used. Content analysis was used to explore the speeches. Results: the criterion of choice was the relationship of the companion with the puerpera or availability at the moment. Most were the newborn's own companion and father. In the analysis, the statements were organized into one category-Criteria for choosing the companion-and four subcategories: How participants were informed about the right to have a companion; Reactions generated by the companion's presence; Companion's attitudes that caused discomfort; Desire to have another companion. Conclusion: paternal participation proved to be a relevant criterion for parturients.

Descriptors: Patient Companions. Labor. Nursing Care. Humanized Childbirth.

\footnotetext{
Enfermeira Obstétrica. Doutora em Enfermagem. Professora Associada da Universidade Federal de Minas Gerais. Belo Horizonte, Minas Gerais, Brasil. torcata@enf.ufmg.br.http://orcid.org/0000-0002-9177-9958.

Estudante de Enfermagem. Universidade Federal de Minas Gerais. Belo Horizonte, Minas Gerais, Brasil. http://orcid.org/0000-000 I-75 I 7-946 I

Estudante de Enfermagem. Universidade Federal de Minas Gerais. Belo Horizonte, Minas Gerais, Brasil. http://orcid.org/0000-0003-1669-1064

Enfermeira. Doutora em Enfermagem. Professora Adjunto da Universidade Federal de Minas Gerais, Belo Horizonte, Minas Gerais. Brasil. http://orcid.org/00000002-6870-84|4.

5 Enfermeira. Universidade Federal de Minas Gerais. Enfermeira Obstetra Hospital das Clínicas da Universidade Federal de Minas Gerais. Belo Horizonte, Minas Gerais, Brasil. http://orcid.org/0000-0003- | 5 | 3-7803.
} 
Objetivo: describir los criterios que llevan las parturientas a elegir a su compañero durante el trabajo de parto. Método: estudio descriptivo con un enfoque cualitativo, desarrollado en la maternidad de un hospital público de enseñanza en Belo Horizonte, Minas Gerais, Brasil. Participaron 17 mujeres puerperas mayores de 18 años. Para la recopilación de datos, se utilizó la entrevista semiestructurada. El análisis de contenido se utilizó para explorar los discursos. Resultados: el criterio de elección era la relación del compañero con la puerpera o la disponibilidad en el momento. La mayoría era el propio compañero y padre del recién nacido. En el análisis, las declaraciones se organizaron en una categoría - Criterios para elegir el compañero-y cuatro subcategorías: Como las participantes se informaron sobre el derecho a tener un compañero; Reacciones generadas por la presencia del compañero; Actitudes del compañero que causaron malestar; Deseo en tener otro compañero. Conclusión: la participación paterna resultó ser un criterio relevante para las parturientas.

Descriptores: Compañeros del Paciente. Trabajo de Parto. Cuidado de Enfermería. Parto Humanizado.

\section{Introdução}

As transformações do papel das mulheres na sociedade contemporânea não lhes retiram o desejo de seu protagonismo no processo de gestação, parturição e assistência prestada nesse período. Até o século XIX, as mulheres eram protagonistas nesse momento da vida e durante o trabalho de parto, que rotineiramente ocorria em ambiente doméstico, com a presença da família e assistência prestada por parteiras. A partir do século XX, médicos e enfermeiras assumiram a responsabilidade da assistência à parturiente com o intuito de qualificar profissionalmente essa ação utilizando recursos tecnológicos. Isso resultou na redução do empoderamento das mulheres e perda de espaço dos acompanhantes, além de posterior perda do espaço de atuação do enfermeiro nesse contexto ${ }^{(1)}$.

Atualmente, a crítica ao modelo tecnocrático vigente impulsionou a busca por uma assistência humanizada, pautada em evidências científicas, em práticas comprovadamente benéficas e no resgate da autonomia das mulheres. Essa proposta inclui a presença de um acompanhante de livre escolha da mulher durante todo o processo de parturição e nascimento ${ }^{(2)}$.

Os diversos benefícios advindos da presença do acompanhante nesse processo já são reconhecidos e incluem segurança, confiança e tranquilidade transmitidas às mulheres ${ }^{(3)}$. Redução significativa de intervenções desnecessárias é um dos aspectos observados com a presença do acompanhante, além de oportunizar um processo de parturição singular, natural e fisiológico, aliado ao protagonismo da mulher ${ }^{(4)}$. Essa boa prática já era recomendada pela Organização Mundial de Saúde (OMS) desde 1985, com o lançamento do documento "Tecnologias Apropriadas para o Parto e Nascimento"(5).

No Brasil, com o objetivo de assegurar a melhoria do acesso, da cobertura e da qualidade do acompanhamento pré-natal, bem como da assistência no parto e puerpério às gestantes e ao recém-nascido, foram criados programas e portarias na perspectiva de garantir os direitos das mulheres e suas famílias. Dentre eles, destaca-se a publicação da Lei n ${ }^{\circ} 11.108$, de 2005, que obriga as instituições de saúde a permitirem a presença de um acompanhante de livre escolha da mulher durante todo o trabalho de parto, parto e pós-parto imediato ${ }^{(6)}$. Posteriormente, esse direito foi ratificado nas diretrizes da Rede Cegonha, estratégia de atenção à saúde das mulheres, de 2011, enfatizando a importância da inserção dos acompanhantes durante o referido período $^{(7)}$.

Em 2018, foi lançado o documento Intrapartum Care for a Positive Childbirth Experience, da OMS, com as recomendações e as respectivas evidências mais atuais que reforçam a importância do papel do acompanhante no processo de parturição e nascimento ${ }^{(8)}$.

A relevância da presença do acompanhante durante o processo de parturição e nascimento e a grande diversidade deles nas maternidades, fatos observados pelas autoras, nas vivências pregressas, ocasionaram interesse em conhecer 
os motivos pelos quais aqueles haviam sido escolhidos. Acredita-se que este estudo poderá contribuir para que os profissionais orientem melhor as gestantes na escolha do seu acompanhante durante o trabalho de parto.

O objetivo deste estudo é descrever os critérios que levam a parturiente a escolher o seu acompanhante durante o trabalho de parto.

\section{Método}

Trata-se de um estudo descritivo, de abordagem qualitativa. A coleta de dados foi realizada na maternidade de um hospital de ensino público de grande porte, situado no município de Belo Horizonte (MG). Participaram da pesquisa 17 puérperas. Os critérios de inclusão foram: idade igual ou superior a 18 anos, ter acompanhante de sua escolha durante todo o trabalho de parto, parto e puerpério sem intercorrências e estar com seu recém-nascido em alojamento conjunto há pelo menos seis horas, período necessário para que a puérpera se alimente, descanse e interaja com seu recém-nascido. Assim, estará mais disposta e tranquila para participar do estudo.

As entrevistas ocorreram nos meses de dezembro de 2018 a fevereiro de 2019, utilizando-se questionário semiestruturado. As falas foram gravadas e transcritas o mais próximo possível da entrevista, primando-se pela fidedignidade. As mulheres foram informadas sobre a natureza do estudo e consentiram com a participação por meio da assinatura do Termo de Consentimento Livre e Esclarecido (TCLE) em duas vias. Alguns acompanhantes estavam presentes durante a entrevista, por escolha das mulheres, não demonstrando interferência ou relevância em relação à veracidade das respostas. O questionário semiestruturado foi desenvolvido pelos pesquisadores para este estudo e as perguntas norteadoras estavam relacionadas ao critério de escolha do acompanhante, sentimentos e incômodos da puérpera em relação ao seu acompanhante.

As depoentes foram identificadas nas falas pela consoante P (participante) seguida pelo número correspondente à ordem em que as entrevistas foram realizadas. O sigilo da fonte das informações foi mantido, conforme compromisso ético assumido. A aplicação do questionário ocorreu até que as falas começaram a se repetir, sendo a saturação percebida na $17^{\mathrm{a}}$ entrevista.

Os dados coletados foram analisados utilizando-se como metodologia a análise de conteúdo de Laurence Bardin, que se caracteriza como um conjunto de instrumentos e técnicas que levam em consideração as significações. Procura conhecer aquilo que é "falado" nos gestos e nas expressões e o que está "por trás" das palavras, por meio de três etapas: pré-análise, que consiste na leitura flutuante e organização dos depoimentos de acordo com o objetivo do estudo; exploração do material, quando é realizado o recorte de contexto das falas das participantes e agregação dos conteúdos, resultando em categorias; e inferência, que compreende o tratamento dos resultados, mediante a organização desses nas categorias emergidas e na discussão fundamentada na literatura científica existente sobre o assunto ${ }^{(9)}$.

Foram respeitados os aspectos éticos e legais preconizados pela Resolução n ${ }^{\circ} 580 / 2018$ do Conselho Nacional de Saúde, que aprova as diretrizes e normas regulamentadoras de pesquisas envolvendo seres humanos. A pesquisa teve início após a aprovação do Comitê de Ética em Pesquisa da Universidade Federal de Minas Gerais (UFMG), com o Certificado de Apresentação para Apreciação Ética (CAAE) 54746516.6.00005149, e do Hospital Risoleta Tolentino Neves (HRTN), com Parecer no 15/2016.

\section{Resultados e Discussão}

As 17 puérperas do estudo tinham entre 18 a 40 anos de idade, com média de 28,1 anos. Observou-se que todos os acompanhantes apresentavam algum vínculo familiar com as mulheres, dentre eles, 10 (dez) eram companheiros e pais dos recém-nascidos, quatro eram mães das puérperas, duas eram irmãs e uma a tia, totalizando $58,82 \%$ de participação paterna 
e $41,18 \%$ de participação de outras figuras do sexo feminino.

Esses resultados possibilitaram observar a relevância da participação paterna durante esse momento. Sabe-se que a presença do pai desde o pré-natal é importante, a fim de que ele esteja apto a praticar a paternidade ativa e consciente, além de compartilhar com a mulher as responsabilidades e os cuidados com a criança ${ }^{(10)}$. No entanto, percebeu-se que a companhia de outra mulher também é importante e pode ser mais desejada pela gestante ou parturiente, em detrimento da presença do pai da criança.

A imersão nas falas permitiu que emergisse uma categoria - Critérios de escolha do acompanhante -, que atendia ao objetivo do estudo, e quatro subcategorias, que descreveram como e quando se deu a escolha do acompanhante: Como as participantes informaram-se sobre o direito de ter um acompanhante; Reações geradas pela presença do acompanhante; Atitudes do acompanhante que causaram incômodo; e Desejo de ter outro acompanhante.

\section{Critérios de escolba do acompanhante}

A maioria das participantes escolheu os seus companheiros e pais dos recém-nascidos como acompanhantes. O principal motivo para tal escolha foi o fato de serem seus companheiros e/ou pais dos bebês e também pela cumplicidade e parceria da relação. Isso foi evidenciado em falas como:

Ele sempre teve muito presente. Ele também falou: $\mathrm{Ab}$, eu quero estar lá! E eu não quis tirar isso dele. (P3).

É meu esposo, compartilha a vida comigo. É o pai. Tinha que ser ele. ( $\mathrm{P} 4)$.

Essas falas traduzem a expectativa de grande parte das mulheres em relação à presença do companheiro e pai da criança no momento do parto.

A participação do homem nesse evento é importante para o fortalecimento do vínculo entre o casal e para a construção da paternidade participativa e afetiva ${ }^{(11)}$. A presença do pai no processo de nascimento do filho possibilita o estabelecimento de um vínculo precoce com o recém-nascido, e também melhor preparo e afirmação de sua paternidade ${ }^{(12)}$. Estas afirmativas atestam a expectativa que as puérperas deste estudo demonstraram, ao expressar que não pensaram em outra pessoa, que não seus companheiros naquele momento.

As participantes que escolheram a mãe, irmã ou tia como acompanhantes justificaram: Foi ela [mãe] que me acompanhou o tempo todo né? [...]
o pai não mora em BH. Ele é um frouxo e também não
ia aguentar. (P2).

Porque mãe é mãe né? [...] Eu acho que seria a pessoa ideal pra ficar do meu lado. (P14).

Ela [irmã] é a pessoa mais próxima de mim. Eu acho que, neste momento, tem que ser uma pessoa mais próxima. (P5).

Era a única pessoa [tia] que tava perto no momento, sem trabalhar [...] foi a única no momento de desespero. (P6).

Algumas das razões pelas quais as mulheres optam por outro acompanhante em detrimento do companheiro estão relacionadas à indisponibilidade, devido ao vínculo empregatício, e à dificuldade da pessoa para lidar com sangue e dor e, consequentemente, a falta de estrutura emocional para ajudá-las naquele momento ${ }^{(13)}$. Esta evidência atesta os relatos deste estudo.

Observa-se que todas as acompanhantes possuíam algum laço consanguíneo com a puérpera. O parto é reconhecido como um evento familiar e social relevante, e não como uma responsabilidade exclusiva das mulheres. Isso se dá de forma positiva, uma vez que a proximidade da relação proporciona, à parturiente, uma experiência de satisfação, além de amenizar e facilitar a vivência da maternidade ${ }^{(14)}$.

Contudo, os depoimentos das participantes revelaram que nem sempre a acompanhante foi a pessoa que seria a escolhida, mas, sim, a pessoa disponível no momento. No entanto, conforme os relatos, mesmo sendo a pessoal disponível para acompanhá-la, proporcionou-lhe segurança e tranquilidade.

Como as participantes informaram-se sobre o direito de ter um acompanhante

A maioria das participantes já tinha conhecimento sobre seu direito à presença de um 
acompanhante durante todo o processo de parturição e nascimento. Em alguns depoimentos foi possivel confirmar a importância de se abordar o direito de ter o acompanhante nas consultas de pré-natal, uma vez que algumas das puérperas entrevistadas foram informadas sobre esse direito durante as consultas, conforme as falas a seguir:

Na última consulta do posto de saúde [...] eles me aconsetharam a ter uma pessoa me acompanhando. (P5).

No pré-natal. A enfermeira do posto me falou numa consulta. (P8),

Considerando o pré-natal e o nascimento como momentos singulares para cada mulher, os profissionais de enfermagem que atuam na perspectiva da educação em saúde como prática inerente ao cuidado, e outros profissionais da área da saúde que conduzem esses momentos, devem assumir o papel de educadores, de forma interdisciplinar, compartilhando saberes e buscando gerar nas mulheres a autoconfiança para viver a gestação, o parto e o puerpério de maneira positiva ${ }^{(15-16)}$.

Algumas puérperas ficaram sabendo da possibilidade de ter um acompanhante por amigos e familiares:

Ah, eu já sabia! Tenho duas irmãs que já tiveram neném, ai sempre falaram comigo que tinha que ter um acompanhante. (P12).

Na verdade, todo mundo chegou em mim e falou: você precisa de um acompanhante. (P14).

Confirmando o texto da Lei $\mathrm{n}^{\circ} 11.108$, de 2005, que obriga as instituições de saúde a permitirem a presença de um acompanhante de livre escolha da mulher durante todo trabalho de parto, parto e pós-parto imediato ${ }^{(6)}$, a Agência Nacional de Vigilância Sanitária (ANVISA) publicou, em 3 de junho de 2008, a Resolução RDC $\mathrm{n}$ ㅇ 36. Esta resolução regulamenta e normatiza padrões de assistência e funcionamento dos serviços de atenção obstétrica e neonatal e preconiza que os serviços de saúde devem permitir a presença de acompanhante de livre escolha da mulher no acolhimento, trabalho de parto, parto e pós-parto imediato, além de apresentar estrutura física adequada e segura ${ }^{(17)}$. Esse direito é reforçado pelas diretrizes da Rede Cegonha que, em 2011, buscou assegurar à mulher atenção humanizada durante a gravidez, parto e puerpério, dentre outros direitos ${ }^{(7)}$. Uma das entrevistadas relatou ter pesquisado na internet sobre a possibilidade de ter o acompanhante:

Já tinha um tempinbo que vinha pesquisando isso aí sobre ter acompanbante, olhando na internet. (P17).

Esta fala expressa a relevância do acesso à informação pela internet, de forma a proporcionar autonomia à gestante na busca por conhecimentos necessários para requerer seus direitos.

Após 15 anos da sanção da Lei do acompanhante, ainda existem mulheres que desconhecem os direitos que garantem a presença de um acompanhante de sua livre escolha no período do pré-parto, parto e puerpério imediato, o que constitui um desafio no campo da saúde reprodutiva ${ }^{(18)}$. Este fato também foi comprovado no presente estudo, quando duas mulheres relataram que só foram informadas deste direito, ao darem entrada na maternidade.

Aqui no [....] que eu fiquei sabendo disso de acompanhante [...] perguntei à recepcionista. (P1).

Eu não sabia, até chegar aqui na maternidade. (P16).

Essas falas traduzem falhas na assistência pré-natal, momento em que a mulher deveria ser informada sobre o direito de ter um acompanhante de livre escolha durante o processo de parturição e nascimento, podendo, assim, planejar melhor com o acompanhante de sua escolha. Há de se levar em consideração que o pré-natal deve ser um espaço para promover educação em saúde, levar informações e conhecimentos adequados às gestantes acerca de seus direitos, concedendo-lhes autonomia ${ }^{(19-20)}$.

\section{Reações geradas pela presença do} acompanhante

Todas as entrevistadas manifestaram sentimentos positivos relacionados aos seus acompanhantes, em especial a segurança transmitida por eles, conforme pode ser observado: 
Eu fiquei super à vontade. Pra mim foi tranquilíssimo [...] não poderia ter outra pessoa melhor. (P1).

Eu me senti mais calma, mais tranquila com ele do meu lado. (P14).

A presença do acompanhante proporciona à mulher sentimentos de fortalecimento, segurança, amparo, superação e conforto. Portanto, compartilhar esse momento e desfrutar de tais sentimentos no parto, evento considerado estressante, pode gerar bons desfechos no nascimento $^{(21)}$, Os relatos das participantes deste estudo corroboram essa afirmação. Para a maioria das entrevistadas, os acompanhantes fizeram tudo o que estava ao seu alcance:

Ficou [a mãe] comigo o tempo todo. Me deu calma, a gente rezou juntas até o último segundo. (P2).

Ele ficou todo molhado. Ficou até debaixo do chuveiro. Acho que ele ajudou do jeito que pôde. (P3).

Os fragmentos de falas estão de acordo com a literatura, ao apontarem que alguns acompanhantes mostraram-se proativos, mesmo diante das emoções e ansiedades proporcionadas pelo momento vivido ${ }^{(12)}$. Infere-se, assim, que, apesar de se sentirem ansiosos, inseguros e preocupados, os acompanhantes procuraram não demonstrar esses sentimentos às parturientes.

\section{Atitudes do acompanhante que causaram incômodo}

Algumas entrevistadas relataram que seus acompanhantes tomaram atitudes que lhes causaram algum incômodo:

Ela só ficou mexendo no telefone, não ficava me ajudando. (P8).

Eu mandava ele chamar a enfermeira, ele ia, procurava e não achava ela, e eu apavorava, achando que ia morrer e aí, até taquei água nele para mandar ele sair do quarto e ir procurar a enfermeira. (P3).

Ele ficava conversando comigo enquanto eu tinha contração, e eu não queria conversar. Aí me incomodou um pouco. (P9).

Estas falas refletem uma presença passiva do acompanhante. Esse comportamento pode estar relacionado ao sentimento de despreparo, devido ao desconhecimento do processo do trabalho de parto, e pela falta de informações prévias sobre a importância de seu papel junto à parturiente ${ }^{(22-23)}$. Entretanto, observa-se, nas falas, que as atitudes positivas dos acompanhantes foram mais evidentes.

\section{Desejo de ter outro acompanhante}

Algumas participantes manifestaram o desejo de ter a mãe ao seu lado durante o trabalho de parto.

Pensei, minha mãe [...] porque, se não fosse ele, poderia ser ela pra estar comigo. (P17).

Essa vontade vai ao encontro da literatura, que relata o desejo das mulheres de terem um acompanhante que passe segurança, apoio e a tranquilidade que elas buscam. Muitas vezes, é a figura da mãe que exerce esse papel na vida delas $^{(13)}$.

Uma entrevistada, que teve como acompanhante sua irmã, disse que gostaria de ter tido a presença do marido nesse momento:

Pensei em ter meu marido aqui comigo no lugar dela [irmã] [...] ele tava trabalhando. (P15).

Essa última fala confirma e exemplifica a já citada idealização quanto à presença do companheiro e pai da criança no momento do trabalho de parto, parto e nascimento, ainda que, por vezes, não seja concretizada por múltiplas razões, como, por exemplo, o compromisso laboral $^{(13)}$

Vale ressaltar que, mesmo já sendo comprovada a importância da participação do acompanhante, em algumas instituições ainda há restrição quanto à sua presença sob diferentes justificativas. Dentre elas, estão a falta de preparo da equipe de saúde para acolher o acompanhante, a insegurança por parte dos profissionais, por acreditarem que serão observados e vigiados, além da justificativa da estrutura física da sala de parto não comportar mais ninguém além da parturiente e da equipe ${ }^{(1)}$.

Nesse sentido, a equipe de enfermagem é a protagonista no papel de fazer cumprir a Lei do Acompanhante, contribuindo para o cuidado individualizado e para o respeito às subjetividades e direitos das parturientes ${ }^{(14)}$. Também é 
imprescindivel o papel do enfermeiro durante o pré-natal como importante agente na consolidação das informações e na prestação de cuidados qualificados ${ }^{(23)}$.

Apesar de ser um estudo qualitativo, entende-se que a investigação em outros cenários e com outros participantes é necessária, tendo em vista a diversidade de acompanhantes presentes no dia a dia das maternidades. Entende-se que isto promoverá mais evidências para embasar estratégias de cuidado que atendam às necessidades das parturientes e de seus acompanhantes, dos profissionais de saúde e dos gestores das instituições.

\section{Conclusão}

Destacou-se, nesta investigação, a participação paterna, momento que não poderia ser compartilhado com outra pessoa, além de seus companheiros, segundo as entrevistadas. A presença de outra pessoa decorreu do vínculo afetivo ou da indisponibilidade do companheiro. Contudo, independente de quem seja o acompanhante, chama a atenção os benefícios dessa presença.

O presente estudo poderá contribuir com a melhoria da assistência prestada à parturiente. $\mathrm{Na}$ condição de gestante bem informada, planejará melhor a participação do acompanhante e buscará um cuidado mais qualificado e baseado em evidências. Acrescenta-se que esforços devem ser envidados para a garantia do cumprimento da lei do acompanhante, tendo em vista os benefícios dessa presença durante o processo de parturição. Reconhece-se também a importância da enfermeira não somente enquanto pré-natalista, mas pela sua relevante participação nas ações educativas e no acompanhamento do trabalho de parto, parto e puerpério.

\section{Colaborações:}

1 - concepção, projeto, análise e interpretação dos dados: Torcata Amorim, Larissa Aarestrup de Aquino Aguiar, Mariana de Assis Cabral Pereira;
2 - redação do artigo e revisão crítica relevante do conteúdo intelectual: Torcata Amorim, Larissa Aarestrup de Aquino Aguiar, Mariana de Assis Cabral Pereira, Juliana de Oliveira Marcatto, Kelly Cristina Almeida Borgonove;

3 - aprovação final da versão a ser publicada: Torcata Amorim, Larissa Aarestrup de Aquino Aguiar, Mariana de Assis Cabral Pereira, Juliana de Oliveira Marcatto, Kelly Cristina Almeida Borgonove.

\section{Referências}

1. Ferreira KA, Madeira LM. O significado do acompanhante na assistência ao parto para a mulher e familiares. Enfermagem Obstétrica [Internet]. 2016 jan/abr [cited 2019 Aug 10];3(1):e29. Available from: http://www.enfo.com.br/ojs/ index.php/EnfObst/article/view/29/28

2. Demarche-Frutuoso L, Brüggemann $\mathrm{O}$, Monticelli M, Oliveira M, Costa R. Percepções do acompanhante de escolha da mulher acerca da organização e ambiência do centro obstétrico. J res: fundam care. Online. 2017 Apr/Jun;9(2):363-70. DOI:http://dx.doi.org/10.9789/2175-5361.2017.v9i2. 363-370

3. Monguilhott JJC, Brüggemann OM, Freitas PF, d'Orsi E. Nascer no Brasil: a presença do acompanhante favorece a aplicação das boas práticas na atenção ao parto na região Sul. Rev saúde pública. 2018;52:1. DOI: https://doi. org/10.11606/S1518-8787.2018052006258

4. Pereira SB, Diaz CMG, Backes MTS, Ferreira CLL, Backes DS. Good practices of labor and birth care from the perspective of health professionals. Rev Bras Enferm [Internet]. 2018 [cited 18 Aug 2019];71(Suppl 3):1313-9. Available from: http://www.scielo.br/scielo.php?script=sci_ arttext\&pid=S0034-71672018000901313\&lng=en

5. World Health Organization. Appropriate Technology for Birth. Lancet [Internet]. 1985 [cited 23 Jul 2020];2(8452):436-7. Available from: https://www.ncbi.nlm.nih.gov/pubmed/2863457

6. Brasil. Presidência da República. Lei $n^{\circ} 11.108$, de 7 de abril de 2005. Altera a Lei no 8.080, de 19 de setembro de 1990, para garantir às parturientes o direito à presença de acompanhante durante $\mathrm{O}$ trabalho de parto, parto e pós-parto imediato, no âmbito do Sistema Único de Saúde - SUS. Diário Oficial da União [Internet]. Brasília (DF); 20057 abr 
[cited 2019 Aug 20]. Available from: http://www. planalto.gov.br/ccivil_03/_Ato2004-2006/2005/ Lei/L11108.htm

7. Brasil. Ministério da Saúde. Portaria oำ 1.459, de 24 de junho de 2011. Institui, no âmbito do Sistema Único de Saúde (SUS), a Rede Cegonha [Internet]. Brasília (DF); 2011 [cited 2019 Aug 20]. Available from: http://bvsms.saude.gov.br/bvs/saudelegis/ gm/2011/prt1459_24_06_2011.html

8. World Health Organization. WHO recommendations on intrapartum care for a positive childbirth experience [Internet]. Geneva; 2018 [cited 2019 Oct 14]. Available from: https://apps.who.int/iris/bitstream/handle/ 10665/260178/9789241550215-eng.pdf

9. Bardin L. Análise de conteúdo. 6a ed. Lisboa: Edições 70; 2016.

10. Rodrigues TA, Pinheiro AKB, Silva AA, Castro LRG, Silva MB, Fonseca LMB. Qualidade dos registros da assistência pré-natal na caderneta da gestante. Rev baiana enferm. 2020;34:e 35099. DOI: 10.18471/rbe.v34.35099

11. Silva ALS, Nascimento ER, Coelho EAC. Práticas de enfermeiras para promoção da significação, participação e autonomia de mulheres no parto normal. Esc Anna Nery. 2015 set;19(3):424-43. DOI: $10.18471 /$ rbe.v34.35099

12. Ribeiro JP, Gomes GC, Silva BT, Cardoso LS, Silva PA, Strefling ISS. Participação do pai na gestação, parto e puerpério: refletindo as interfaces da assistência de enfermagem. Espaç Saúde (Online). 2015;16(3):73-82. DOI: http:// dx.doi.org/10.22421/1517-7130.2015v16n3p73

13. Francisco BS, Souza BS, Vitório ML, Zampieri MFM, Gregório VRP. Percepções dos pais sobre suas vivências como acompanhantes durante o parto e nascimento. REME - Rev Min Enferm. 2015;19(3):567-75. DOI: http://www.dx.doi.org/ $10.5935 / 1415-2762.20150044$

14. Souza SRRK, Gualda DMRA. A experiência da mulher e de seu acompanhante no parto em uma maternidade pública. Texto contexto enferm. 2016;25(1):e4080014. DOI: http://dx.doi. org/10.1590/0104-0707201600004080014

15. Camillo B, Nietsche E, Salbego C, Cassenote L, Dal-Osto D, Böck A. Health education actions in primary attention to pregnant and puerperal women: integrative review. J Nurs UFPE on line. 2016;10(6):4894-901. DOI: https://doi.org/10.5205/1981-8963-v10i6a11270 p4894-4901-2016

16. Bélanger-Lévesque MN, Pasquier M, Roy-Matton N, Blouin S, Pasquier JC. Maternal and paternal satisfaction in the delivery room: a cross-sectional comparative study. BMJ Open. 2014;4(2):e004013. DOI: 10.1136/bmjopen2013-004013

17. Agência Nacional de Vigilância Sanitária. Resolução RDC no 36, de 3 de junho de 2008. Dispõe sobre Regulamento Técnico para Funcionamento dos Serviços de Atenção Obstétrica e Neonatal [Internet]. Diário Oficial da União. Brasília (DF), 20088 jul [cited 2019 Oct 16]. Available from: http:// bvsms.saude.gov.br/bvs/saudelegis/anvisa/2008/ res0036_03_06_2008_rep.html

18. Sá AMP, Alves VH, Rodrigues DP, Branco MRBL, Paula E, Marchiori GRS. The right to access and accompanying of labor and childbirth: women's point of view. J Nurs UFPE on line. $2017 \mathrm{Jul} ; 11(7)$ : 2683-90. DOI: https://doi.org/10.5205/1981-8963v11i7a23440p2683-2690-2017

19. Ragagnin MV, Marchiori MRCT, Diaz CMMG, Nicolli T, Pereira SB, Silva LD. The approach of the nursing team about the humanized childbirth during the prenatal: a narrative review. $J$ res: fundam care online. 2017 out/nov;9(4):1177-82. DOI: http://dx.doi.org/10.9789/2175-5361.2017. v9i4.1177-1182

20. Santos ALS, Oliveira ARS, Amorim T, Silva UL. O acompanhante no trabalho de parto sob a perspectiva da puérpera. REUFSM Rev Enferm UFSM. 2015;5(3):531-40. DOI: http://dx.doi. org/10.5902/2179769217337

21. Souza TA, Mattos DV, Matão MEL, Martins CA. Sentimentos vivenciados por parturientes em razão da inserção do acompanhante no processo parturitivo. Rev enferm UFPE on line. 2016 dez;10(Supl 6):4735-40. DOI: 10.5205/ reuol.8200-71830-3-SM.1006sup201604

22. Souza M, Wall M, Thuler A, Freire M, Santos E. Experience of the parturient's assistant in the delivery process. J Nursing UFPE on line. 2018 Mar;12(3):626-34. DOI: https://doi.org/10. 5205/1981-8963-v12i3a230979p626-634-2018

23. Johansson M, Fenwick J, Premberg A. A metasynthesis of fathers' experiences of their partner's labour and the birth of their baby. Midwifery. 2015;31(1):9-18. DOI: 10.1016/j.midw.2014.05.005 
Torcata Amorim, Larissa Aarestrup de Aquino Aguiar, Mariana de Assis Cabral Pereira, Juliana de Oliveira Marcatto, Kelly Cristina Almeida Borgonove

24. Costa D, Arruda L, Magalhães A, Abreu L, Ponte K, Freitas C. Nursing care in prenatal and patient safety: integrative review. J Nursing UFPE on line. 2016 Nov;10(6):4909-19. DOI: 10.5205/ reuol.8200-71830-3-SM.1006sup201625
Recebido: 14 de maio de 2020

Aprovado: 20 de julho de 2020

Publicado: 8 de outubro de 2020

A Revista Baiana de Enfermagem utiliza a Licença Creative Commons - Atribuição-NãoComercial 4.0 Internacional. https://creativecommons.org/licenses/by-nc/4.0/ Este artigo é de acesso aberto distribuído sob os termos da Licença Creative Commons (CC BY-NC). Esta licença permite que outros remixem, adaptem e criem a partir do seu trabalho para fins não comerciais. Embora os novos trabalhos tenham de lhe atribuir o devido crédito e não possam ser usados para fins comerciais, os usuários não têm de licenciar esses trabalhos derivados sob os mesmos termos. 